\title{
REACTIVITY OF LABORATORY AND INDUSTRIAL LIMES
}

\author{
J.-M. Commandré*, S. Salvador and A. Nzihou \\ Ecole des Mines d'Albi-Carmaux, Laboratoire de Génie des Procédés des Solides Divisés, Albi, \\ France.
}

\begin{abstract}
Quicklimes produced in an industrial kiln have a very low hydration activity compared to those produced in the laboratory. In this study, we seek to explain these differences in reactivities by providing quantitative data on the kinetics of the two mechanisms involved in the production of quicklime: the calcination of limestone to produce quicklime, and the undesirable sintering of quicklime. The first mechanism increases the specific surface area of the product from a few $\mathrm{m}^{2} \mathrm{~g}^{-1}$ to more than $80 \mathrm{~m}^{2} \mathrm{~g}^{-1}$, making the quicklime highly reactive: the time to react with water is less than $10 \mathrm{~s}$. The second mechanism reduces the specific surface area down to a few $\mathrm{m}^{2} \mathrm{~g}^{-1}$-which is typical for an industrial quicklime-and severely reduces its reactivity: the time to react with water is around $15 \mathrm{~min}$. The impact of the local temperature and of the local partial pressure of $\mathrm{CO}_{2}$ is quantified for both mechanisms, by experimenting the two extreme cases of pure $\mathrm{N}_{2}$ atmosphere and pure $\mathrm{CO}_{2}$ atmosphere using specially designed laboratory apparatus. Some correlation between the quicklime reactivity and the specific surface area is found. The work demonstrates that industrial furnace calcining large limestone pellets, leads to low reactivity quicklimes both because the calcination temperature is too high and the $\mathrm{CO}_{2}$ pressure is too elevated.
\end{abstract}

Keywords: lime; reactivity; sintering; calcination; $\mathrm{CO}_{2}$.

\section{INTRODUCTION}

* Correspondence to: Dr J.-M. Commandré, Ecole des Mines d'Albi-Carmaux, Laboratoire de Génie des Procédés des Solides Divisés, UMR 2392 CNRS Campus Jarlard, route de Teille, 81013 Albi CT Cedex 09, France.

E-mail:

commandr@enstimac.fr
1998; Zhong and Bjerle, 1993). Borgwardt (1985) found from his entrained flow reactor studies that $90 \%$ of calcination conversion was reached in $0.25 \mathrm{~s}$ for $10 \mu \mathrm{m}$ limestone particles at $1000^{\circ} \mathrm{C}$, but for differential reactor tests, the same calcination conversion tooks $40 \mathrm{~s}$ to be reached for $6 \mu \mathrm{m}$ particles at $710^{\circ} \mathrm{C}$.

The BET surface area and the porosity of quicklime depends on calcination conditions. Borgwardt (1989a, b) found that the $\mathrm{CaO}$ had a minimum grain size and a maximum surface area of $104 \mathrm{~m}^{2} \mathrm{~g}^{-1}$ immediately following $\mathrm{CaCO}_{3}$ decomposition. Beruto et al. (1980) calcined $3-10 \mu \mathrm{m} \quad \mathrm{CaCO}_{3}$ under vacuum at $510^{\circ} \mathrm{C}$, the measured $\mathrm{BET}$ surface area of the quicklime being $133 \mathrm{~m}^{2} \mathrm{~g}^{-1}$. Zhong and Bjerle (1993) reach a specific surface of $110 \mathrm{~m}^{2} \mathrm{~g}^{-1}$ in an entrained flow reactor used to calcine limestone particles. They found that specific surface increases with reaction temperature until $1000^{\circ} \mathrm{C}$, then decreases.

The kinetics of limestone calcination is known to be slowed down if the partial pressure of $\mathrm{CO}_{2}$ is increased (Borgwardt, 1989b; Fuertes et al., 1991; Hills, 1968; Hu and Scaroni, 1996; Ingraham and Marier, 1963; Khinast et al., 1996; Zhong and Bjerle, 1993). The effect of the $\mathrm{CO}_{2}$ partial pressure on rate of calcination is taken into 
account by including a correcting factor in the kinetic equation. This factor is based on a equilibrium $\mathrm{CO}_{2}$ partial pressure calculation (Rao et al., 1989; Turkdogan et al., 1973). Zhong and Bjerle (1993) have shown that $\mathrm{CaCO}_{3}$ decomposition is clearly decreased by increasing $\mathrm{CO}_{2}$ partial pressure. When $\mathrm{CO}_{2}$ partial pressure exceeds its equilibrium partial pressure, $\mathrm{CaCO}_{3}$ cannot decompose.

The effect of $\mathrm{CO}_{2}$ on quicklime specific surface is remarkable. Samples calcined at $1123 \mathrm{~K}$ by Rubiera et al. (1991) have a surface of $25 \mathrm{~m}^{2} \mathrm{~g}^{-1}$ under $\mathrm{N}_{2}$ whereas those calcined in $10 \% \mathrm{CO}_{2}$ have an area of $7 \mathrm{~m}^{2} \mathrm{~g}^{-1}$. In an industrial process, three phenomena can potentially increase the $\mathrm{CO}_{2}$ pressure inside pellets, when decarbonation occurs:

(1) $\mathrm{CO}_{2}$ is not removed instantaneously from the inside of the pellets, and its partial pressure can be higher at the heart of the pellet than close to its surface;

(2) $\mathrm{CO}_{2}$ leaving the pellet is not evacuated instantaneously from the surface of the pellet, and its partial pressure can be higher at the surface of the particle than around the particle;

(3) the gas that sweeps the particle can be $\mathrm{CO}_{2}$ rich due to $\mathrm{CO}_{2}$ release by the pellets upstream.

Because of these factors, achieving full decarbonation of the pellets within several hours requires operating temperatures much higher than in the ideal case i.e., when the $\mathrm{CO}_{2}$ partial pressure is zero. Indeed, the temperature in a industrial kiln reaches $1000-1300^{\circ} \mathrm{C}$, and the decarbonation time required ranges from 2 to $24 \mathrm{~h}$ (Seidel et al., 1980; Tashimo et al., 2000), while full calcination can be achieved at $900^{\circ} \mathrm{C}$ within less than $1 \mathrm{~min}$ in the laboratory.

An unfortunate consequence of the high temperatures involved is the sintering reaction. Some authors (Borgwardt, 1989a; Tashimo et al., 2000; Zhong and Bjerle, 1993) have shown that the sintering rate is accelerated in presence of $\mathrm{CO}_{2}$ or $\mathrm{H}_{2} \mathrm{O}$. The increase both in temperature and in $\mathrm{CO}_{2}$ concentration enhances the sintering of $\mathrm{CaO}$ (Beruto et al., 1984; Borgwardt, 1989a) which results in a decrease in the surface area. Shi et al. (2002) have shown that increasing the firing temperature results in a more perfect lattice of $\mathrm{CaO}$, a denser structure, a lower free energy of the crystal surfaces and a lower hydration activity of $\mathrm{CaO}$. In short, the hydration activity of $\mathrm{CaO}$ is a macroscopic reflection of its microstructure (Shi et al., 2002). As a result, an industrial quicklime requires more than $10 \mathrm{~min}$ for hydration in water, whereas quicklimes produced in laboratory at temperature lower than $1100^{\circ} \mathrm{C}$ require less than 4 min (Kantiranis, 2003; Shi et al., 2002; Xu et al., 1998). Dheilly et al. (1998) have produced extremely porous quicklime. Its surface area is equal to $5.1 \mathrm{~m}^{2} \mathrm{~g}^{-1}$; this corresponds to a product that would be known in industrial terms as 'highly reactive'. Campbell et al. (1988) have shown that at a given temperature the hydration activity is reduced when calcination time increases. Shi et al. (2002) also show that hydration activity is reduced when temperature increases at a given residence time.

In this work, the kinetics for each of the two reactionslimestone calcination and quicklime sintering-has been characterized. The impact of the $\mathrm{CO}_{2}$ partial pressure on both reactions is also quantitatively characterized by realizing the two reactions under the two extreme conditions for atmosphere: pure $\mathrm{N}_{2}$ and pure $\mathrm{CO}_{2}$.
The quicklime hydration activity is determined for each experiment; a correlation between the quicklime specific surface and its hydration activity has been investigated.

\section{EXPERIMENTS}

Experiments were achieved by using three types of devices:

- Limestone calcination experiments in a specially designed laboratory crossed fixed-bed reactor enabling precise control of the calcination temperature and of the $\mathrm{CO}_{2}$ partial pressure. This made it possible to produce a very high reactivity quicklime.

- Lime sintering experiments, in which a very high reactivity quicklime was submitted to temperatures ranging from 1100 to $1300^{\circ} \mathrm{C}$ for $2 \mathrm{~h}$ in a muffle furnace.

- Because of the very high reactivity of some of the quicklimes produced and of the small quantities obtained (a few $\mathrm{g}$ ), a specific new device was developed to measure extinction duration in water even in the case of durations as small as $15 \mathrm{~s}$.

\section{Calcination Set-Up and Procedure}

The difficulty in designing a fixed-bed reactor for limestone calcination lies in the need to guarantee:

- that the $\mathrm{CO}_{2}$ released by each grain is rapidly evacuated from the inside of the particle to its surface;

- that $\mathrm{CO}_{2}$ content in the atmosphere around all grains inside the bed is similar and controlled.

The 'crossed' fixed bed that was developed is shown in Figure 1. The bed is crossed by all of the atmosphere gases. The flow rate of these gases is sufficiently high $\left(4 \mathrm{I} \mathrm{min}^{-1}\right.$ at STP) to ensure that the concentration of $\mathrm{CO}_{2}$ produced during limestone calcination under $\mathrm{N}_{2}$ atmosphere never exceeds $1 \%$ at the exit of the bed.

In order to ensure a homogenous flow of gases through the limestone bed, and a good contact between the particles and the gas, limestone particles are mixed with $1.5 \mathrm{~mm}$ diameter ruby balls. These balls are inert and do not interact with limestone or quicklime, and their melting point is higher than $2000 \mathrm{~K}$.

The apparatus consists of an external $30 \mathrm{~mm}$ i.d. and a $330 \mathrm{~mm}$ long, electrically heated quartz tube. The gas passes through the limestone bed is previously preheated in the annular space between the external and the internal tube. The flow of gas is controlled by a mass flow meter/controller. Gases are exhausted at the bottom of the internal tube. The pressure on top of the bed is measured; this pressure remains close to atmospheric pressure, proving that the gases are well evacuated.

Each test is operated as follows. The limestone is mixed with the ruby balls, and is deposited on the filtering sheet: the bed height is around $20 \mathrm{~mm}$. The sweeping gas (nitrogen or $\mathrm{CO}_{2}$ ) feeds the reactor while the sample is kept beside it. When the reactor is stabilised at the fixed calcination temperature, the internal tube containing limestone is rapidly introduced.

Experiments are carried out at the calcination temperatures and retentions time indicated in Table 1. At the end of the calcination period, the internal tube is taken out 


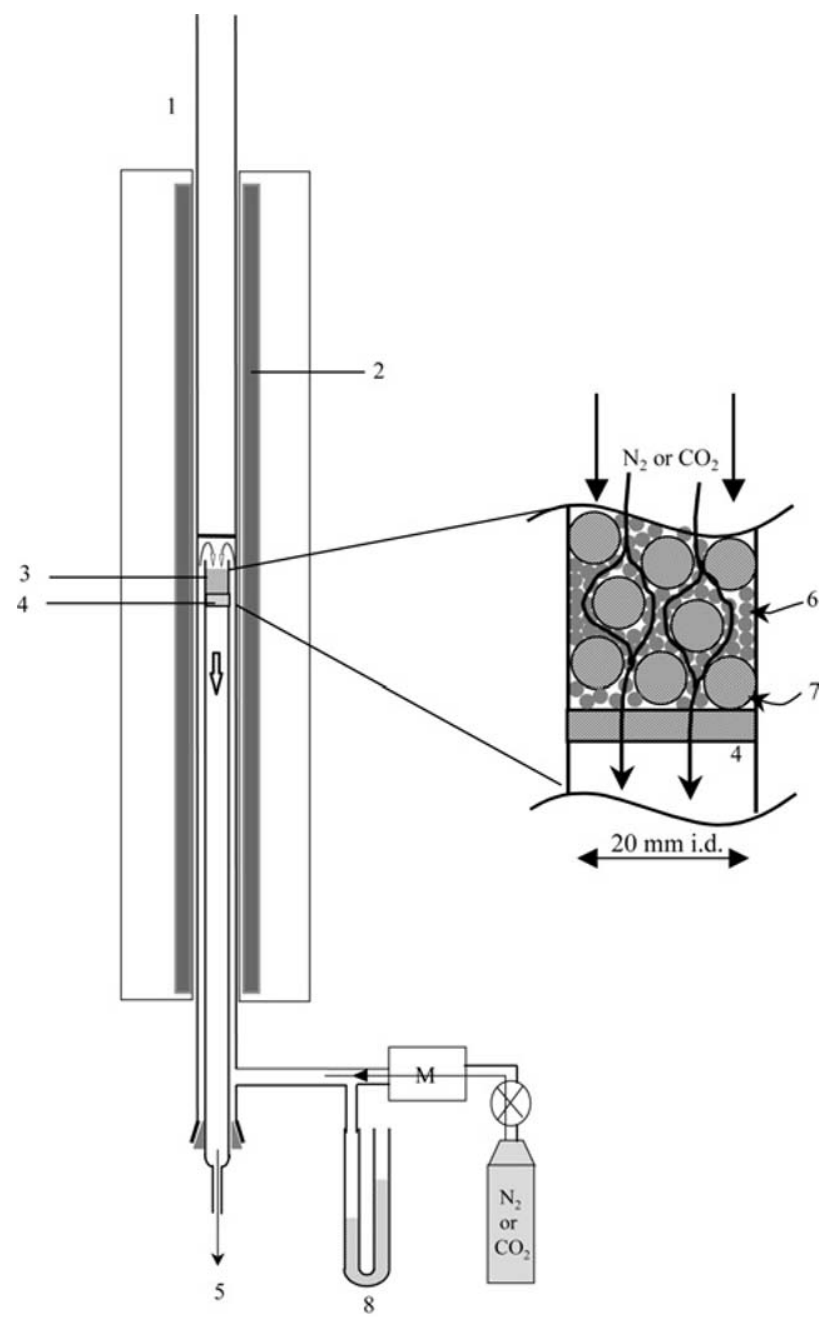

Figure 1. Crossed fixed bed. (1) Quartz tube; (2) electrical heater; (3) particles bed; (4) filtering sheet; (5) exhaust gases; (6) lime particles; (7) ruby balls; (8) water column manometer; $\mathrm{M}$-mass flow meter/ controller; $\mathrm{N}_{2}$-nitrogen; $\mathrm{CO}_{2}-$ carbon dioxide.

of the reactor. The calcination reactions are stopped rapidly as the sample is quenched by connecting the exit of the internal tube to a pump and sucking fresh air through the sample.

Table 1. Experiments realised in crossed fixed-bed reactor; calcination temperature, duration of experiment, gas used as atmosphere in reactor, and calcination conversion after reaction.

\begin{tabular}{lcccc}
\hline Atmosphere & $\begin{array}{c}\text { Calcination } \\
\text { temperature } \\
\left({ }^{\circ} \mathrm{C}\right)\end{array}$ & $\begin{array}{c}\text { Duration } \\
(\mathrm{s})\end{array}$ & $\begin{array}{c}\text { Calcination } \\
\text { conversion } \\
(\%)\end{array}$ & $\begin{array}{c}\text { Specific } \\
\text { surface } \\
\left(\mathrm{m}^{2} \mathrm{~g}^{-1} \text { lime }\right)\end{array}$ \\
\hline $\mathrm{N}_{2}$ & 600 & 3600 & 10.11 & \\
$\mathrm{~N}_{2}$ & 600 & 5400 & 24.28 & 79.28 \\
$\mathrm{~N}_{2}$ & 700 & 1860 & 50.09 & \\
$\mathrm{~N}_{2}$ & 700 & 1920 & 53.81 & \\
$\mathrm{~N}_{2}$ & 700 & 2520 & 73.04 & 46.66 \\
$\mathrm{~N}_{2}$ & 750 & 1860 & 95.06 & 32.81 \\
$\mathrm{CO}_{2}$ & 90 & 2700 & 36.1 & 15.64 \\
$\mathrm{CO}_{2}$ & 910 & 1920 & 59.7 & 10.08 \\
$\mathrm{CO}_{2}$ & 920 & 1200 & 71.8 & 11.26 \\
\hline
\end{tabular}

\section{Characterization of the Limestone}

The sample used in this work was natural limestone from a quarry. In order to limit the pressure drop in the bed, the limestone was dried and the $315-400 \mu \mathrm{m}$ fraction was selected by sieving. It is expected that the small size of the particles will give a small $\mathrm{CO}_{2}$ concentration gradient inside a grain. Table 2 gives the result of the chemical analysis, density and specific surface area measurements of the limestone. $\mathrm{Ca}, \mathrm{Na}$ and $\mathrm{K}$ compositions were measured by induced coupled plasma; ultimate analysis was used for C. The composition is very similar to literature (Seidel et al., 1980). Mass loss measurements realised in TG experiments under air in the temperature $400-600^{\circ} \mathrm{C}$ show that, in the case of our limestone, the amount of organic carbon is less than $0.2 \%$.

The skeletal density was obtained by helium pycnometry (Micromeritics Accupyc 1330). Its value was around $2700 \mathrm{~kg} \mathrm{~m}^{-3}$. The surface area was measured using nitrogen adsorption (Micromeritics Gemini) at $77 \mathrm{~K}$ and calculated with the BET equation. The value of the surface area of limestone was low at $1.6 \mathrm{~m}^{2} \mathrm{~g}^{-1}$, which is in agreement with the literature (Cremer and Nitsch, 1962; Ingraham and Marier, 1963; Rubiera et al., 1991; Tashimo et al., 2000).

\section{Characterization of Quicklime}

The calcination degree of all the quicklimes produced was determined by measuring the residual loss on ignition. A mass $m_{\mathrm{i}}$ was deposited into a quartz crucible as a thin layer (less than $2 \mathrm{~mm}$ ), and introduced in a muffle furnace at $975^{\circ} \mathrm{C}$ for $30 \mathrm{~min}$. The final mass $\mathrm{m}_{\mathrm{f}}$ was then measured. The calcination progress, $\tau$, was expressed by

$$
\tau=\frac{m_{\mathrm{i}}-m_{\mathrm{f}}}{0.44 m_{\mathrm{i}}}
$$

where the term $0.44 m_{\mathrm{i}}$ is the theoretical maximal mass loss by $\mathrm{CO}_{2}$ release after complete calcination of initial limestone ( 0.44 is the ratio of molar mass of $\mathrm{CO}_{2}$ and of $\mathrm{CaCO}_{3}$ ).

The specific surface area and the density of the quicklimes produced were measured by $\mathrm{N}_{2}$ adsorption (BET) and $\mathrm{He}$ pycnometry respectively.

The hydration reaction of quicklime is an exothermic reaction and can be expressed by

$$
\mathrm{CaO}_{(\mathrm{S})}+\mathrm{H}_{2} \mathrm{O} \rightarrow \mathrm{Ca}(\mathrm{OH})_{2_{(\mathrm{S})}}+64.5 \mathrm{~kJ} \mathrm{~mol}_{\mathrm{CaO}}^{-1}
$$

Quicklime reactivity is typically measured using the water extinction test following the European standard procedure (NF EN 549-2, 2002); a mass of $150 \mathrm{~g}$ of lime is introduced into $600 \mathrm{~g}$ of water in an adiabatic receiver (Dewar), shaken by a magnetic stirrer. A thermometer placed in the suspension measures the temperature of water, which increases due to the heat released during hydration of $\mathrm{CaO}$ and then stabilizes to a final value. Different characteristics can be derived from this test:

- a static property: the maximal temperature reached after complete quicklime hydration;

- a dynamic property: the time to reach this maximal temperature, which characterizes the activity of the quicklime (Maciel-Camacho et al., 1997; French norm, 2002). 
Table 2. Specific surface area, density and chemical analysis of limestone.

\begin{tabular}{|c|c|c|c|c|c|c|c|c|c|}
\hline & $\begin{array}{l}\text { Specific surface } \\
\qquad\left(\mathrm{m}^{2} \mathrm{~g}^{-1}\right)\end{array}$ & $\begin{array}{l}\text { Density } \\
\left(\mathrm{g} \mathrm{cm}^{-3}\right)\end{array}$ & $\begin{array}{l}\mathrm{Ca} \\
(\%)\end{array}$ & $\begin{array}{c}\mathrm{K} \\
(\%)\end{array}$ & $\begin{array}{l}\mathrm{Na} \\
(\%)\end{array}$ & $\begin{array}{l}\mathrm{C} \\
(\%)\end{array}$ & $\begin{array}{l}\mathrm{H} \\
(\%)\end{array}$ & $\begin{array}{l}N \\
(\%)\end{array}$ & $\begin{array}{l}\mathrm{S} \\
(\%)\end{array}$ \\
\hline Limestone $315-400 \mu \mathrm{m}$ & 1.6 & 2.69 & 45.36 & 0.63 & 1.0 & 11.81 & 0.0 & 0.0 & 0.0 \\
\hline
\end{tabular}

The quicklime produced in the laboratory experiments was available in quantities of a few grams only, and a specific device had to be developed. Shi et al. (2002) determined the hydration activity by conductive microcalorimetry. This device allows the heat flux released during hydration to be measured, but the values obtained are far from results found in standard devices. We used a $10 \mathrm{ml}$ flask in which $1.5 \mathrm{~g}$ of quicklime was introduced together with a magnetic bar (see Figure 2). Three thermocouples, which crossed the cap of the flask, were placed in the flask. The flask was then put on a $15 \mathrm{~mm}$ thick insulating material and laid in a drum (Figure 2) in order to protect the flask from eventual forced convection with air in the room.

Water was then rapidly fed into the flask and the temperature variation of the mixture was recorded.

Because of the small size of the experiment, heat losses from the water and quicklime mixture into the environment cannot be neglected; even insulating the flask did not prevent heat losses. A thermal model was therefore developed to take account of heat losses. Preliminary experiments were carried out (without quicklime) in which we measured the temperature decrease of hot water placed in the flask. It was found that the expression of the heat losses following equation:

$$
\Phi=4.72 \cdot S \cdot\left(T_{\text {sample }}-T_{\text {amb }}\right)^{0.25}
$$

provides a very good description. By applying this model, the temperature curve versus time is identical in this test to that measured for an industrial lime with the standard test. This technique enabled extinction durations as short as $10 \mathrm{~s}$ to be measured using a sample mass of $1.5 \mathrm{~g}$ only.

\section{Sintering Set-Up and Procedure}

The sintering mechanism was studied in a specific AUBRY furnace which allows samples to be heated up to $1600^{\circ} \mathrm{C}$. A quicklime with a high surface area was first prepared. This quicklime was then used to study sintering reaction. The high reactivity quicklime was prepared using a muffle furnace

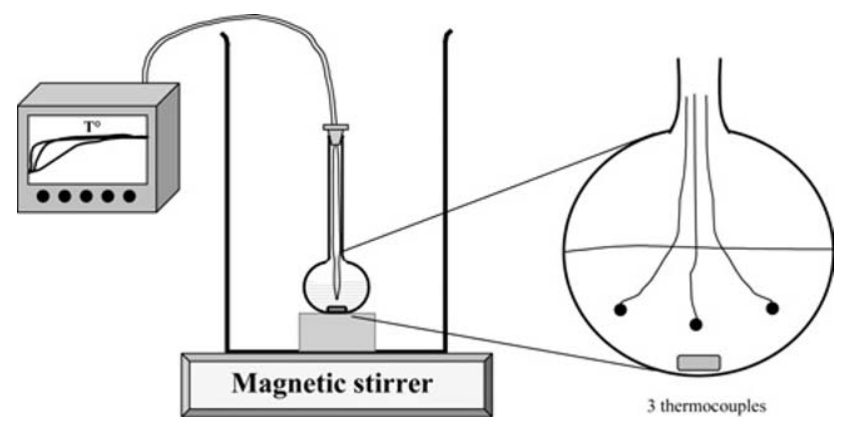

Figure 2. Lime activity measurement device. and calcining limestone at $750^{\circ} \mathrm{C}$ for $2 \mathrm{~h} 50 \mathrm{~min}$. The surface area of this quicklime was $15.18 \mathrm{~m}^{2} \mathrm{~g}_{\mathrm{CaO}}^{-1}$.

Sintering experiments were carried out under $\mathrm{N}_{2}$ and under $\mathrm{CO}_{2}$ atmospheres, between 1100 and $1300^{\circ} \mathrm{C}$. A mass of $4 \mathrm{~g}$ of quicklime was put inside a $6 \mathrm{~cm}$ diameter cylinder with a bed height of less than $5 \mathrm{~mm}$; this crucible was then placed in the furnace. The sample was heated at $10^{\circ} \mathrm{C} \mathrm{min}^{-1}$ until the selected sintering temperature was reached. Then, the temperature was maintained constant for $2 \mathrm{~h}$. Finally, the sample was cooled at $10^{\circ} \mathrm{C} \mathrm{min}-1$.

\section{RESULTS AND DISCUSSION \\ Calcination Kinetics}

The kinetics of limestone calcination under $\mathrm{N}_{2}$ and $\mathrm{CO}_{2}$ atmosphere was studied using data from experiments carried out in the crossed fixed bed reactor. It is clear from these results that calcining limestone under $\mathrm{CO}_{2}$ atmosphere requires a much higher temperature $\left(900-920^{\circ} \mathrm{C}\right)$ than under the $\mathrm{N}_{2}$ atmosphere $\left(600-700^{\circ} \mathrm{C}\right)$.

A plot using the Arrhenius representation should help in interpreting these values. Given the small size of the particles and the high degree of control of the nature of the atmosphere around each grain, a simple first order kinetic model can be adopted, and will be validated further. The reaction kinetics can be expressed by

$$
\frac{d m_{\mathrm{CaCO}_{3}}}{d t}=-k m_{\mathrm{CaCO}_{3}}
$$

which is equivalent to

$$
\frac{d(1-\tau)}{d t}=k(1-\tau)
$$

with

$$
m_{\mathrm{CaCO}_{3}}=m_{\mathrm{f}}-0.56 m_{\mathrm{i}}
$$

we obtain

$$
k=-\frac{\ln (1-\tau)}{t_{r}}
$$

where $t_{\mathrm{r}}$ is the residence time $(\mathrm{s})$, and $k$ is the kinetic rate $\left(\mathrm{s}^{-1}\right)$ of the calcination reaction. The kinetic rate under $\mathrm{N}_{2}$ and $\mathrm{CO}_{2}$ atmosphere are plotted simultaneously in Figure 3. For a given atmosphere, the experimental results follow a straight line in the Arrhenius representation, which indicates that the adopted kinetic model correctly describes the reaction.

The calcination kinetic rate under $\mathrm{CO}_{2}$ atmosphere is much smaller than that found under $\mathrm{N}_{2}$ atmosphere. At a given temperature, i.e., on a vertical line, several decades separate the two kinetic rates. The activation energies-determined from the slopes of the curves-are 180 and $1077 \mathrm{~kJ} \mathrm{~mol}^{-1}$ for calcination under $\mathrm{N}_{2}$ and under $\mathrm{CO}_{2}$ atmospheres 


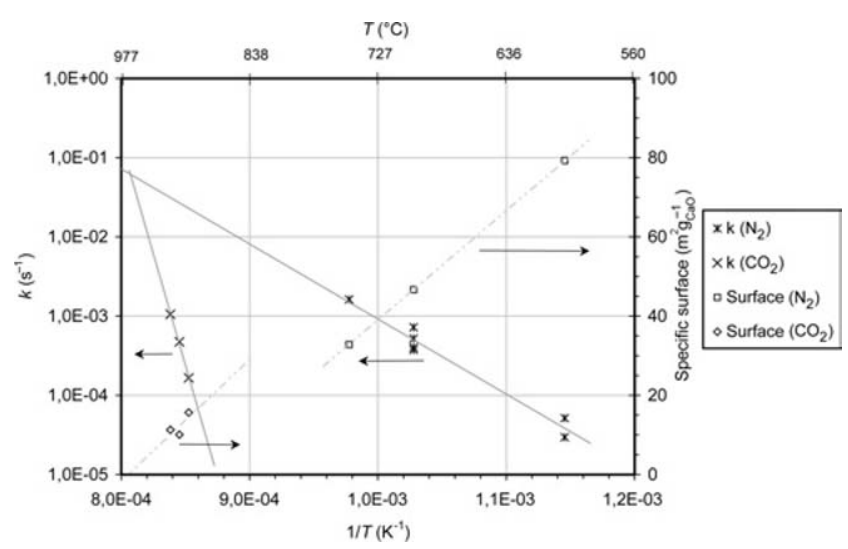

Figure 3. Calcination kinetics and specific surface area during limestone calcination under $\mathrm{N}_{2}$ and $\mathrm{CO}_{2}$ atmosphere. Surface: specific surface area of samples $\left(\mathrm{m}^{2} \mathrm{~g}_{\mathrm{CaO}}^{-1}\right)$.

respectively. The slope of the curve is clearly higher for the experiments under $\mathrm{CO}_{2}$ than for the experiments under $\mathrm{N}_{2}$ atmospheres. If one extrapolates the two curves to higher temperatures, they cross at a temperature close to $960^{\circ} \mathrm{C}$ $\left(1 / T=8 \cdot 1.10^{-4} \mathrm{~K}^{-1}\right)$. This means that at this temperature, a $\mathrm{CO}_{2}$ atmosphere should not slow down the reaction kinetics any more. This result is in agreement with literature (Tashimo et al., 1999; Zhong and Bjerle, 1993).

We have also plotted in Figure 3 the specific surface area of the quicklimes obtained versus the calcination temperature. Since the calcination of limestone is not complete, we have expressed the specific surfaces in $\mathrm{m}^{2} \mathrm{~g}^{-1}$ of $\mathrm{CaO}$ and not in $\mathrm{m}^{2} \mathrm{~g}^{-1}$ of total mass $\left(\mathrm{CaO}+\mathrm{CaCO}_{3}\right)$. Figure 3 shows that very high specific surfaces can be developed if calcination is achieved at a low temperature: the quicklime obtained at $600^{\circ} \mathrm{C}$ has a specific surface area as high as $80 \mathrm{~m}^{2} \mathrm{~g}^{-1}$. When the calcination temperature is increased, the specific surface area decreases to $30 \mathrm{~m}^{2} \mathrm{~g}^{-1}$ for a calcination at $750^{\circ} \mathrm{C}$. The same decrease in the specific surface area for increased temperatures is observed in the case of experiments under $\mathrm{CO}_{2}$ atmosphere. Moreover, all the quicklimes obtained under $\mathrm{CO}_{2}$ atmosphere-and at a higher temperature than under $\mathrm{N}_{2}$ atmosphere-exhibit smaller specific surfaces than quicklimes obtained under $\mathrm{N}_{2}$ atmosphere. This result is in agreement with the literature (Rubiera et al., 1991), and can probably be attributed to $\mathrm{CaO}$ sintering. Indeed, Glasson (1958) showed that the specific surface area increases during calcium carbonate decomposition until it is complete; then the surface decreases by $\mathrm{CaO}$ sintering. In order to gain understanding of the contribution of sintering, specific experiments were devoted to the study of this phenomenon and are described below.

\section{Sintering}

In a second step, the kinetics of quicklime sintering, when submitted to high temperature, was studied. Results of surfaces obtained after sintering are plotted versus temperature in Figure 4. It can be observed that the specific surfaces are very small after sintering as compared with the surface of the initial quicklime. At $1100^{\circ} \mathrm{C}$, they are $1.65 \mathrm{~m}^{2} \mathrm{~g}^{-1}$ and $1.15 \mathrm{~m}^{2} \mathrm{~g}^{-1}$ under $\mathrm{N}_{2}$ and $\mathrm{CO}_{2}$ respectively. The sintering process has already taken place to a significant extent. The

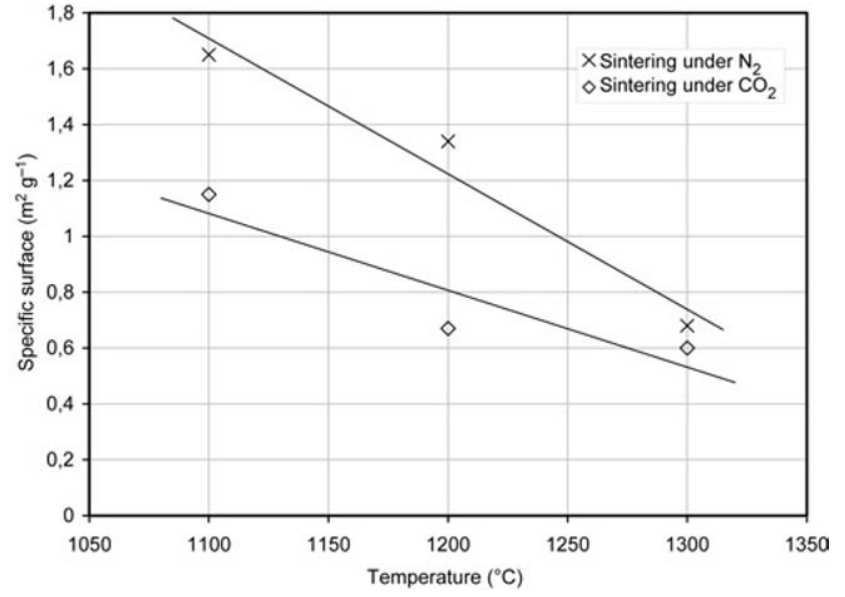

Figure 4. Specific surface after sintering at different temperature under $\mathrm{N}_{2}$ and under $\mathrm{CO}_{2}$ atmosphere (initial lime for all sintering experiments: surface area of $15.18 \mathrm{~m}^{2} \mathrm{~g}^{-1}$ ).

specific surfaces still decrease when temperature is increased to $1300^{\circ} \mathrm{C}$. At this temperature, the surface area falls to $0.68 \mathrm{~m}^{2} \mathrm{~g}^{-1}$ under $\mathrm{N}_{2}$, and at $0.6 \mathrm{~m}^{2} \mathrm{~g}^{-1}$ under $\mathrm{CO}_{2}$.

\section{Quicklime Reactivity}

In this section, the reactivity of quicklime is determined from the water hydration test, and interpretations are proposed on the basis of previous observations. The hydration of quicklime was first realized for all quicklimes obtained after simple calcination. The temperature increase of the quicklime + water mixtures during the hydration tests were recorded versus time. They were converted into degrees Celsius per gram of $\mathrm{CaO}$ and not per gram of $\mathrm{CaO}+\mathrm{CaCO}_{3}$. The motivation for this was to highlight the hydration activity of the reactive fraction of the partially calcined products, excluding the non-reactive limestone fraction left. The results are plotted in Figure 5 for quicklime calcined under $\mathrm{N}_{2}$, and in Figure 6 for quicklime calcined under $\mathrm{CO}_{2}$. As a result of the expression of the results in $\mathrm{m}^{2} \mathrm{~g}_{\mathrm{CaO}}^{-1}$, the final temperature increase observed for all experiments is similar: $55-60^{\circ} \mathrm{C}$; it corresponds to the heat release of the quicklime hydration reaction and is thereabout the same with the data provided by Kantiranis (2003). One can note that once the maximum temperature has been reached, the temperature calculated using the thermal model describing heat losses remains constant, which validates the thermal model.

The hydration reaction of quicklimes produced under $\mathrm{N}_{2}$ in our study is extremely fast: the maximum temperature is reached within less than $10 \mathrm{~s}$. The time to extinguish an industrial quicklime is typically $15-20 \mathrm{~min}$ : there is a drastic difference in reactivity between industrial limes and limes obtained in the laboratory.

In the case of calcination under $\mathrm{CO}_{2}$ atmosphere, the time to reach the maximum temperature is much longer than after calcination under $\mathrm{N}_{2}: 50-500 \mathrm{~s}$. Nevertheless, it is still much shorter than for an industrial quicklime.

The work realized by Shi et al. (2002) has shown that hydration activity of $\mathrm{CaO}$ is a macroscopic reflection of its microstructure. Industrial quicklime, less reactive than our quicklime, has a specific surface area of $4.2 \mathrm{~m}^{2} \mathrm{~g}_{\mathrm{CaO}}^{-1}$ 


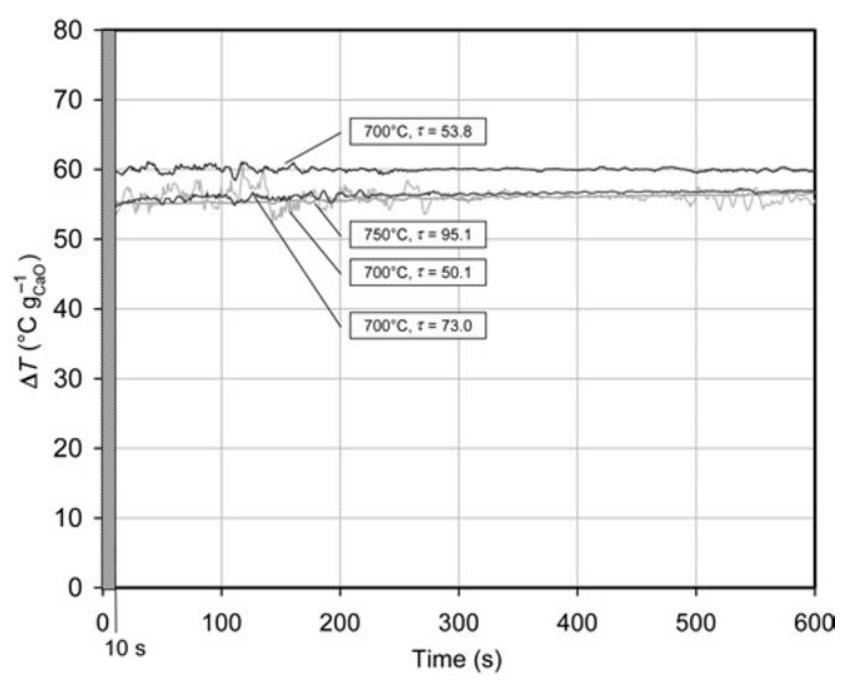

Figure 5. Hydration activity of lime calcined under $\mathrm{N}_{2}$ atmosphere; $10 \mathrm{~s}$ is the time required to start temperature recording; calcination temperature and progress are indicated.

whereas the surface of quicklime produced in our crossed fixed bed is higher than $10 \mathrm{~m}^{2} \mathrm{~g}^{-1}$ whatever the temperature or atmosphere of calcination.

\section{Sintered Quicklime Reactivity}

The hydration activities obtained in the case of sintered quicklimes are presented in Figure 7.

(1) The sintering treatments at 1100,1200 and $1300^{\circ} \mathrm{C}$ under nitrogen atmosphere have clearly increased the time for hydration. It takes 112,308 and 370 s respectively to reach $80 \%$ of the final temperature increase when the non-sintered quicklimes take less than 10 s. The three sintered quicklimes nevertheless still present a much higher activity than the industrial lime.

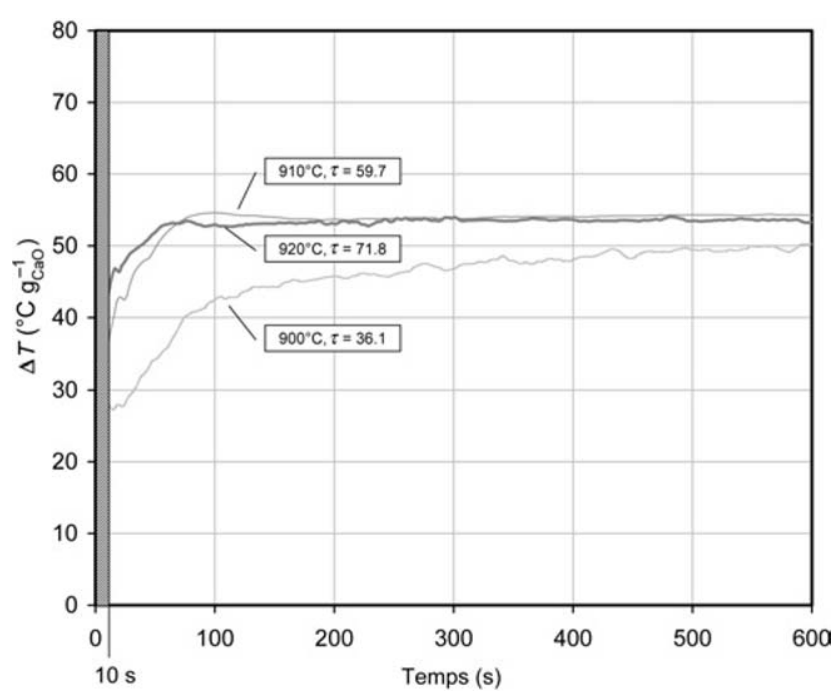

Figure 6. Hydration activity of lime calcined under $\mathrm{CO}_{2}$ atmosphere; $10 \mathrm{~s}$ is the time required to start temperature recording; calcination temperature and progress are indicated.

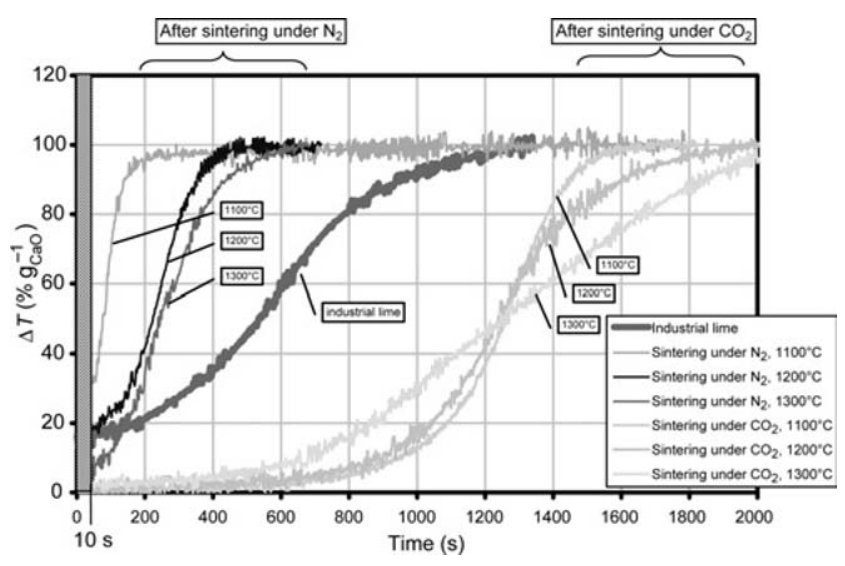

Figure 7. Hydration activity of lime sintered under $\mathrm{N}_{2}$ and $\mathrm{CO}_{2}$; hydration activity and industrial lime produced in packed-bed.

(2) The quicklimes submitted to sintering at 1100, 1200 and $1300^{\circ} \mathrm{C}$ under $\mathrm{CO}_{2}$ atmospheres exhibit very low reactivities: it takes 1386,1438 and 1664 s respectively to reach $80 \%$ of the final temperature increase. The three quicklimes are approximately half as reactive as the industrial lime, and five times less reactive than the quicklimes that have undergone sintering under $\mathrm{N}_{2}$ atmosphere. These results suggest the following interpretation for the low reactivity of an industrial quicklime as compared to laboratory quicklimes. Due to the large size of the pellets, high temperatures are operated in the lime kiln for the calcination to occur in acceptable retention time. Sintering then occurs, and decreases the hydration activity of the quicklime. Nevertheless, it is very probable that the temperature in the industrial kiln does not exceed $1300^{\circ} \mathrm{C}$ : as shown in Figure 7 for quicklime sintered under $\mathrm{N}_{2}$, sintering under $\mathrm{CO}_{2}$-free atmosphere cannot explain the low reactivity of the industrial quicklime. As a consequence, it is likely that sintering occurs under high $\mathrm{CO}_{2}$ partial pressure in the industrial process. It is beyond the scope of this work to establish if the accumulation happens inside each pellet or at the scale of the bed of pellets in the atmosphere gas, but this $\mathrm{CO}_{2}$ accumulation seems to be a drawback of the process

As previous authors did (Borgwardt, 1989a), we have observed that both the nature of the atmosphere gas and the temperature during sintering affect the surface area of the quicklime and its hydration activity. It is of particular interest to try to establish a link between the surface area and the reactivity of the quicklimes.

In Figure 8, we have plotted the time necessary to reach $80 \%$ of the maximal hydration temperature increase (by gram of $\mathrm{CaO}$ ) versus the surface area of sintered quicklime. If one considers the experimental results as two separate families-the $\mathrm{N}_{2}$ sintered quicklimes and the $\mathrm{CO}_{2}$ sintered quicklimes-some correlation is observed between the specific surface area and the reactivity of quicklime: the higher the specific surface area the smaller the time for extinction. If one attempts to fit the experimental results with straight lines, $r^{2}$ of 0.77 and 0.53 only are found for the experiments under $\mathrm{N}_{2}$ and under $\mathrm{CO}_{2}$ atmospheres respectively. If one now considers the results all together, it is not possible to predict the activity of a given quicklime 


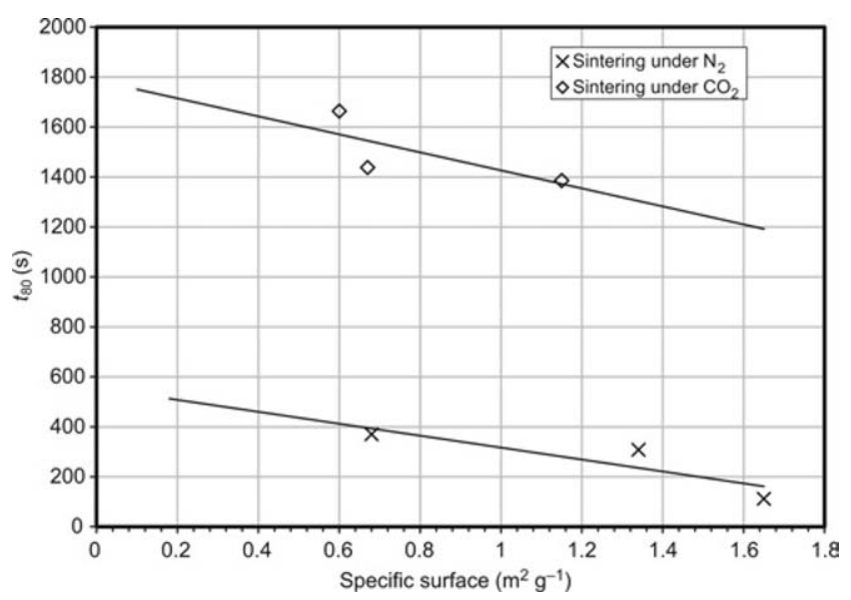

Figure 8 . Time to reach $80 \%$ of the final hydration temperature increase $\left(t_{80}\right)$ versus specific surface after sintering at different temperature under $\mathrm{N}_{2}$ and under $\mathrm{CO}_{2}$ atmosphere.

from the measurement of its surface area only. For instance, two quicklimes with a $0.7 \mathrm{~m}^{2} \mathrm{~g}^{-1}$ surface area obtained under $\mathrm{N}_{2}$ and $\mathrm{CO}_{2}$ atmospheres take 370 and $1438 \mathrm{~s}$ respectively to hydrate.

During calcination under $\mathrm{CO}_{2}$, two kinds of sintering occur: a thermal sintering which also happens for calcination under $\mathrm{N}_{2}$, and a 'chemical' sintering due to $\mathrm{CO}_{2}$ presence. The mechanism of this process is not well understood (Rubiera et al., 1991), although Borgwardt et al. (1986) and Beruto et al. (1984) suggest a catalytic effect from the $\mathrm{CO}_{2}$.

For a given quicklime surface area, the effect of chemical sintering is to increase the time to extinguish during the water extinction test. In conclusion, the time to extinguish for two quicklimes with the same specific surface area was greater when the $\mathrm{CO}_{2}$ concentration was higher i.e., when sintering due to $\mathrm{CO}_{2}$ was effective.

\section{CONCLUSION}

In this work, we sought to explain the difference of hydration activities of quicklimes produced in laboratory and in industry. Very high reactive quicklimes can be produced in the laboratory: it takes less than $10 \mathrm{~s}$ to hydrate them. Such quicklimes were obtained using a fixed bed of limestone particles swept with $\mathrm{N}_{2}$. If calcination is operated under pure $\mathrm{CO}_{2}$ atmosphere, quicklimes presenting high reactivity are obtained, but the time for hydration with water increases to several hundreds of seconds, which is still much shorter than for an industrial quicklime. The presence of $\mathrm{CO}_{2}$ nevertheless drastically reduces the calcination kinetics as compared with $\mathrm{N}_{2}$ atmosphere, but this effect should disappear at temperatures above $960^{\circ} \mathrm{C}$. Sintering phenomena explain the low-reactivity of an industrial quicklime which typically takes more than $600 \mathrm{~s}$ to hydrate with water. The present work shows that a low-reactivity quicklime can be produced from limestone calcined at temperature higher than $1100^{\circ} \mathrm{C}$ and under $\mathrm{CO}_{2}$ atmosphere. A highlyreactive quicklime produced in the laboratory, presenting a specific surface area of several tens of $\mathrm{m}^{2} \mathrm{~g}^{-1}$, is converted to a low specific surface quicklime if sintering is operated at temperatures higher than $1100^{\circ} \mathrm{C}$ for $2 \mathrm{~h}$ under $\mathrm{N}_{2}$; its reactivity is greatly decreased. Nevertheless, such sintered quicklimes are still twice as reactive as an industrial quicklime. Sintering under $\mathrm{CO}_{2}$ atmosphere at the same temperature and retention time result in quicklimes with reactivities of half that of the industrial quicklime. It can therefore be suggested that, in an industrial lime kiln, operating temperatures are too high, inducing quicklime sintering and that also $\mathrm{CO}_{2}$ accumulation is significant and responsible for the low reactivity of the quicklimes that are produced.

In an attempt to correlate the specific surface area of sintered quicklimes with their reactivity, it is shown that some correlation exists among classes of quicklimes sintered under a given atmosphere, but that the knowledge of the specific surface area alone is not sufficient to predict the reactivity of a quicklime obtained under an unknown atmosphere.

\section{REFERENCES}

Beruto, D., Barco, L., Searcy, A.W. and Spinolo, G., 1980, Characterisation of the porous $\mathrm{CaO}$ particles formed by decomposition of $\mathrm{CaCO}_{3}$ and $\mathrm{Ca}(\mathrm{OH})_{2}$ in vacuum, Journal of the American Ceramic Society, 63(2): 439-443.

Beruto, D., Barco, L. and Searcy, A.W., 1984, $\mathrm{CO}_{2}$ catalysed surface area and porosity changes in high surface area $\mathrm{CaO}$ aggregates, Journal of the American Ceramic Society, 67: 512-515.

Borgwardt, R.H., 1985, Calcination kinetics and surface area of dispersed limestone particles, A/Che J, 31(1): 103-111.

Borgwardt, R.H., Roache, N.F. and Bruce, K.R., 1986, Method for variation of grain size in studies of gas-solid reactions involving $\mathrm{CaO}$, Ind Eng Chem Fund, 25(1): 165-169.

Borgwardt, R.H., 1989a, Calcination oxide sintering in atmospheres containing water and carbon dioxide, Ind Eng Chem Res, 28(4): 493-500.

Borgwardt, R.H., 1989b, Sintering of nascent calcium oxide, Chem Eng Sci, 44(1): 53-60.

Campbell, A.J., Job, A.R. and Robertson, J.F., 1988, Lime calcination: time and temperature of calcination expressed as a single variable and the effect of selected impurities on lime properties, ZKG International, 9: 442-446.

Cremer, E. and Nitsch, W., 1962, Uber die geschwindigkeit der $\mathrm{CaCO}_{3}$-zersetzung in abhangigkeit vom CO2-druck, Zeitschrift fur Elektrochemie, 66: 697-702.

Dheilly, R.M., Tudo, J. and Queneudec, M., 1998, Influence of climatic conditions on the carbonation of quicklime, Journal of materials, Engineering and Performance, 7(6): 789-795.

DiBenedetto, A. and Salatino, P., 1998, Modeling attrition of limestone during calcination and sulfation in a fluidised bed reactor, Powder Technol, 95: 119-128.

Fuertes, A.B., Alvarez, D., Rubiera, F., Pis, J.J. and Marban, G.D.R., 1991, Surface area and pore size changes during sintering of calcium oxide particles, Chemical Engineering Communications, 109: 73-88.

Glasson, D.R., 1958, Reactivity of lime and related oxides. I. Production of calcium oxides, Journal of Applied Chemistry, 8(793): 793-797.

Hills, A.W.D., 1968, The mechanism of the thermal decomposition of calcium carbonate, Chem Eng Sci, 23: 297-320.

$\mathrm{Hu}, \mathrm{N}$. and Scaroni, A.W., 1996, Calcination of pulverized limestone particles under furnace injection conditions, Fuel, 75(2): 177-186.

Ingraham, T.R. and Marier, R.H., 1963, Kinetics studies on the thermal decomposition of calcium carbonate, Canadian Journal of Chemical Engineering, 170-173.

Kantiranis, N., 2003, Hydration of high-calcium quicklime with methanol-water mixtures, Construction and Building Materials, 17: 91-96.

Khinast, J., Krammer, G.F., Brunner, C. and Staudinger, G., 1996, Decomposition of limestone: the influence of $\mathrm{CO}_{2}$ and particle size on the reaction rate, Chem Eng Sci, 51(4): 623-634.

Maciel-Camacho, A., Rodriguez Hernandez, H., Hills, A.W.D. and Morales, R.D., 1997, Hydration kinetics of recarbonized lime, ISIJ International, 37(5): 477-483.

NF EN 549-2, 2002, Norme française et européenne, Chaux de construction, partie2: méthode d'essai. 
Potgieter, J.H., Potgieter, S.S., Moja, S.J. and Mulaba-Bafubiandi, A., 2002, An empirical study of factors influencing lime slaking. Part I: Production and storage conditions, Minerals Engineering, 15: 201-203.

Rao, T.R., Gunn, D.J. and Bowen, J.H., 1989, Kinetics of calcium carbonate decomposition, Chem Eng Res Des, 67(1): 38-47.

Rubiera, F., Fuertes, A.B., Pis, J.J., Artos, V. and Marban G., 1991, Changes in textural properties of limestone and dolomite during calcination, Thermochimica Acta, 179: 125-134.

Seidel, G., Huckauf, H. and Stark, J., 1980, Technologie des ciments, chaux, plâtres, Editions Septima.

Shi, H., Zhao, Y. and Li, W., 2002, Effects of temperature on the hydration characteristics of free lime, Cement and Concrete Research, 32: 789-793.

Tashimo, T., Suto, T., Murota, J. and Kato, K., 1999, Calcination of fine limestone particles by a powder-particle fluidized bed, Journal of Chemical Engineering of Japan, 32(3): 374-378.

Tashimo, T., Murota, J., Suto, T. and Kato, K., 2000, Physical properties of lime powder produced by powder-particle fluidized bed, Journal of Chemical Engineering of Japan, 33(3): 365-371.
Turkdogan, E.T., Olsson, R.G., Wriedt, H.A. and Darken, L.S., 1973, Calcination of limestone, Transactions of the Metallurgical Society of AIME, 254(1): 9-21.

Xu, B.A., Giles, D.E. and Ritchie, I.M., 1998, Reactions of lime with carbonate containing solution, Hydrometallurgy, 48: 205-224.

Zhong, Q. and Bjerle, I., 1993, Calcination kinetics of limestone and the microstructure of nascent $\mathrm{CaO}$, Thermochimica Acta, 223: $109-120$.

\section{ACKNOWLEDGEMENT}

This research was supported by SOLVAY group (HSE). This support is gratefully acknowledged. 